(C) Elsevier/INRA

Original article

\title{
Sex chromosome and autosome divergence in Podisma (Orthoptera) in western Europe
}

\author{
JL Bella ${ }^{1 *}, \mathrm{M}$ Westerman ${ }^{2}$, C López-Fernández ${ }^{1}$, \\ J de la Torre ${ }^{1}$, JM Rubio ${ }^{1,3}$, J Gosálvez ${ }^{1}$ \\ 1 Universidad Autónoma de Madrid, Facultad de Ciencias, \\ Departamento de Biología C-XV, Unidad de Genética, 28049 Madrid, Spain; \\ ${ }^{2}$ La Trobe University, Department of Genetics and Human Variation. \\ Bundoora, Victoria 3083 Australia; \\ ${ }^{3}$ University of East-Anglia, School of Biological Sciences, Norwich NR4 7TJ, UK
}

(Received 10 February 1990; accepted 3 December 1990)

Summary - The chromosome complement of 2 chromosome races of the montane grasshopper Podisma pedestris from the Alps (XO and Neo-XY) and the Pyrenees (XO), together with the endemic Iberian related subspecies Podisma ignatii cantabricae and Podisma ignatii carpetana, have been analyzed by means of silver staining and specific fluorochromes. Nucleolar organizer regions activity and the nature and localization of heterochromatin show large differences between populations of $P$ pedestris from the Alps and the Pyrenees. Differences are not found to the same extent between populations of $P$ ignatii and $P$ pedestris from the Alps. Some aspects of the evolutionary colonization of Podisma in meridional Europe are considered.

insect cytogenetics / Orthoptera / chromosome divergence

Résumé - Divergence des chromosomes sexuels et des autosomes chez Podisma (Orthoptère) en Europe méridionale. Le complément chromosonique chez 2 races chromosomiques de la sauterelle Podisma pedestris des Alpes (XO et Neo-XY) et des Pyrénées, ainsi que les sous-espèces Ibériques endémiques, $\mathrm{P}$ ignatii cantabricae et $\mathrm{P}$ ignatii carpetana qui leur sont rattachées, a été analysé par une coloration à l'argent et par des fluorochromes spécifiques. L'activité des régions d'organisation nucléolaire ainsi que la nature et la localisation de l'hétérochromatine montrent de grandes différences chez les populations de $\mathrm{P}$ pedestris des Alpes et des Pyrénées. Nous n'avons pas trouvé les mêmes différences pour les populations de $\mathrm{P}$ ignatii et $\mathrm{P}$ pedestris des Alpes. Certains aspects de la colonisation évolutive de Podisma en Europe méridionale sont discutés.

cytogénétique des insectes / Orthoptère / divergence chromosomique

* Correspondence and reprints 
JL Bella et al

\section{INTRODUCTION}

Podisma pedestris is a montane grasshopper with its European distribution in the Alps, Appenines and Pyrenees. In 1950 Morales-Agacino described a new species within this genus, Podisma ignatii, populations of which are localized on high peaks of the Sistema Ibérico, Sistema Central $(P$ ignatii carpetana) and Cantabrian mountains ( $P$ ignatii cantabricae). The presence of this palearctic element within the Iberian peninsula is of interest because the connection between the Peninsula and Europe contains the Pyrenees, a difficult mountainous barrier. The present disjunct distribution of members of the genus Podisma in the Alps, Appenines, Pyrenees, Cantabrian mountains and Sistema Central seems to be a consequence of the climatic amelioration at the end of the last ice age. Populations would have followed the retreat of the ice to higher levels on the mountains, thereby cutting off gene flow between the populations confined within each area. This might explain the existence of 2 different sex chromosome races of $P$ pedestris (XO and neo-XY) in the Alps, which have subsequently formed a hybrid zone in the Alpes Maritimes (Hewitt, 1975; Hewitt and Barton, 1981) and similarly the presence of a third chromosomal race of this species in the Pyrenees, as distinguished by the distribution of heterochromatin in the autosomes (Gosálvez et al, 1988; Bella et al, 1990). This is a simplification of a probably much more complex process involving successive contacts of parapatric races covering patched areas resulting from sequential contractions and expansions (Hewitt, 1989).

This paper deals with the chromosomal relationships between the endemic Iberian subspecies of $P$ ignatii, and its closest relatives $P$ pedestris in the Pyrenees and $P$ pedestris in the Alps.

\section{MATERIALS AND METHODS}

Fixed testes from adult and fourth instar males of $P$ pedestris from the Alps (XO and XY races) and Pyrenees, and $P$ ignatii from the Sistema Central ( $P$ ignatii carpetana) and Cantabrian mountains ( $P$ ignatii cantabricae) were used. In all cases, testes were removed and fixed in ethanol: acetic acid (3:1). Silver staining was performed according to the method described by Gosálvez et al (1986) which includes treatment with double standard saline citrate solution to obtain better resolution of the position of the active nucleolar organizer regions (NORs). Distamycin A/4-6 diamidino-2-phenylindole (DA/DAPI) and distamycin A/chromomycin $\mathrm{A}_{3}\left(\mathrm{DA} / \mathrm{CMA}_{3}\right)$ are selective fluorescent counterstains which reveal the richness of AT or GC base pairs respectively in certain heterochromatic regions; these were used according to the methodology developed by Schweizer (1976a,b).

Acridine orange (AO) was used to stain C-banded slides because, as Bella et al (1986) reported, the metachromatic characteristics of this fluorochrome can help to differentially stain areas associated with active NOR heterochromatin.

\section{RESULTS}

$P$ pedestris and $P$ ignatii both have a standard acridid karyotype of 22 acrocentric autosomes and an $\mathrm{XO} / \mathrm{XX}$ sex-chromosome system over most of their range of 
distribution. However, over an extensive area in the Alpes Maritimes a neo-XY sex chromosome system is found in $P$ pedestris (Hewitt, 1975). This probably arose as a result of a centric fusion between the original $\mathrm{X}$ and a large autosome (John and Hewitt, 1970).

Before describing the variations observed in the chromosomes of these 2 species we would like to point out some features of the nucleoli localized in the Xchromosome in all the individuals analyzed. The production of ribosomal RNA is localized on the sex chromosome and on certain autosomes in all cases, but with great differences in the levels of activity. While the nucleoli on the autosomes are very small and disperse early in first meiotic prophase, making it difficult to localize them precisely, the activity detected in the $\mathrm{X}$ is so great that it permits its localization at late metaphase- $I$. This nucleolar behaviour is unusual when compared with other grasshoppers (Rufas et al, 1985).

Both the XO and XY races in the Alps show a large active NOR localized in a subdistal position on the $\mathrm{X}$ (fig 1 and table I) and, in both cases, the NOR is associated with a C-positive heterochromatic region which fluoresces an intense green colour when stained with acridine orange (fig 2b). This band strongly contrasts with the orange or yellow/orange fluorescence of the rest of the heterochromatic regions. By contrast, in the Pyrenees, where only the $\mathrm{XO}$ race of $P$ pedestris is present, the large active NOR is proximally placed on the $\mathrm{X}$ (fig 1 , table I) and the heterochromatin-associated band fluoresces green but is not as large or as bright as that found in individuals from the Alps (fig 2A). The XO race of $P$ pedestris from the Pyrenees also differs in the absence of a distal band on the sex chromosome (fig 2A, table I). In general, this latter pattern is found throughout the different valleys in the Spanish Pyrenees (south side), from the east to the west. The one exception comes from a population in Valle de Arán (East Pyrenees) where 2 out of a sample of 20 individuals did not show NOR activity in the $\mathrm{X}$, although the banding response of this chromosome was identical to that found in the $\mathrm{X}$ with an active NOR.

The different individuals of $P$ ignatii carpetana and $P$ ignatii cantabricae all show the same characteristics of banding response and nucleolar activity, this being a large active NOR in the X, localized in a distal position (fig 1 , table I) and associated with a green fluorescent heterochromatic band (fig $2 \mathrm{C}$ ). This band is smaller than that found in the Alpine $\mathrm{X}$ of $P$ pedestris but shows similar characteristics of intense green fluorescence when stained with $\mathrm{AO}$. The positive response to $\mathrm{DA} / \mathrm{CMA}_{3}$ (fig $3 \mathrm{~A}$, table I) shown by the paracentromeric region of the autosomes and sex chromosomes of both subspecies of $P$ ignatii, suggests a heterochromatin rich in GC base pairs. DA/DAPI does not show specific fluorescence and all the chromatin stains homogeneously (fig $3 \mathrm{~B}$, table I). Also in P ignatii there is a complete absence of distal heterochromatic segments in the medium-sized chromosomes. Interestingly, the banding reported in the Pyrenean populations of $P$ pedestris (Gosálvez et al, 1988) is different. Although the distal segments in the medium sized chromosomes are again absent, the paracentromeric heterochromatin shows both AT and GC rich DNA. By contrast, $P$ pedestris in the Alps has distal segments in most of the medium sized chromosomes and an absence of AT rich DNA from the heterochromatin, which is relatively rich in GC base pairs (fig 1, table I). 


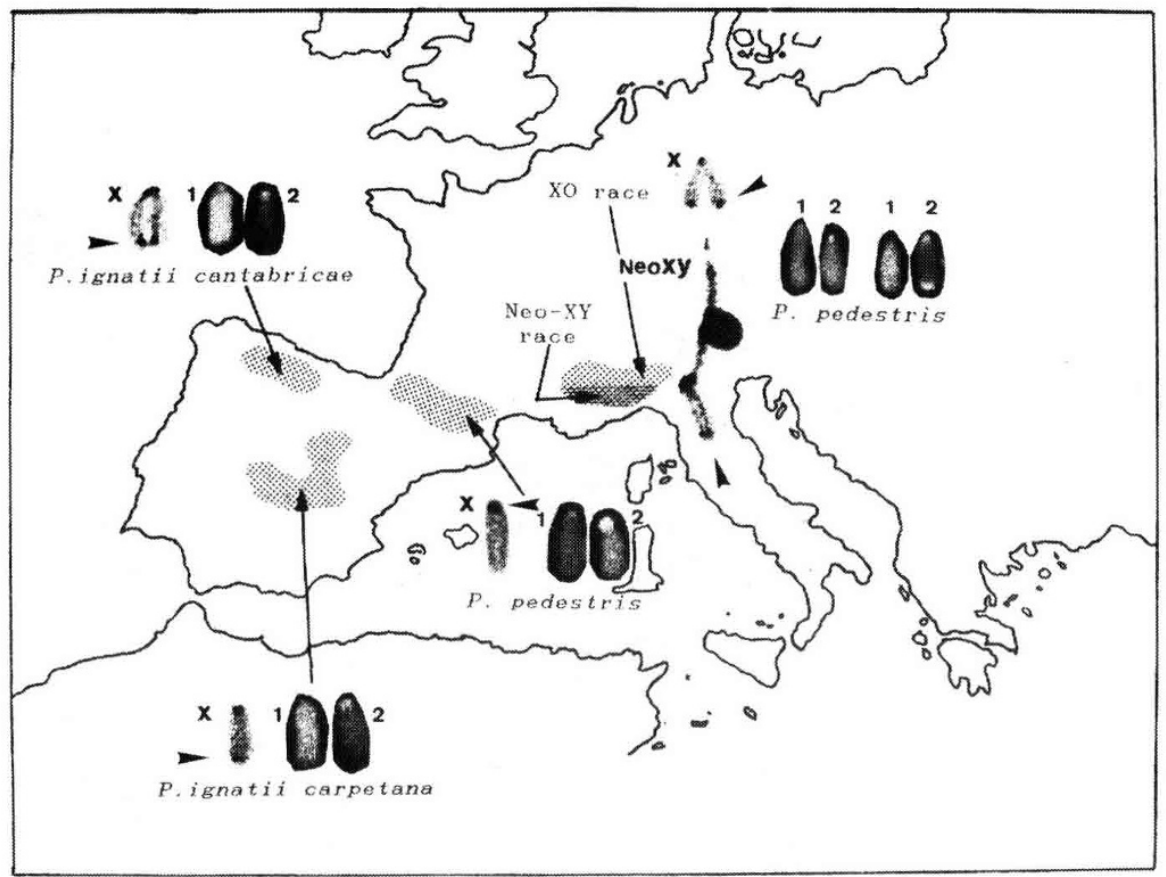

Fig 1. A map showing the distribution of the different chromosome forms in Podisma through west meridional Europe. The $\mathrm{X}$ chromosome shows the localization of the NORs after silver staining (arrows). Selected DA-DAPI (1) and DA-CMA 3 (2) stained chromosomes representing the autosome set are also included. Four chromosomes have been selected from the Alpine races to illustrate the presence of GC-rich distal segments in some medium-sized autosomes.

Table I. Localization of the NORs on the X chromosome and heterochromatin composition after DA/DAPI and DA/CMA 3 treatments of the different species, subspecies and races analyzed. Details on the differences in size of the proximal heterochromatic blocks between the cytotypes are stated in the text.

\begin{tabular}{|c|c|c|c|c|c|}
\hline \multirow[t]{3}{*}{ Species } & \multirow{3}{*}{$\begin{array}{l}X-N O R \\
\text { position }\end{array}$} & \multicolumn{4}{|c|}{ Heterochromatin } \\
\hline & & \multicolumn{2}{|c|}{$A T$-rich } & \multicolumn{2}{|c|}{$G C$-rich } \\
\hline & & \multicolumn{2}{|c|}{ Proximal distal } & \multicolumn{2}{|c|}{ Proximal distal } \\
\hline \multicolumn{6}{|l|}{$P$ pedestris } \\
\hline Alpine XO & Distal & - & - & + & + \\
\hline Alpine Neo-XY & Distal & - & - & + & + \\
\hline Pyrenean XO & Proximal & + & Absent & + & Absent \\
\hline \multicolumn{6}{|l|}{$P$ ignatii } \\
\hline cantabricae & Distal & - & - & + & + \\
\hline carpetana & Distal & - & - & + & + \\
\hline
\end{tabular}



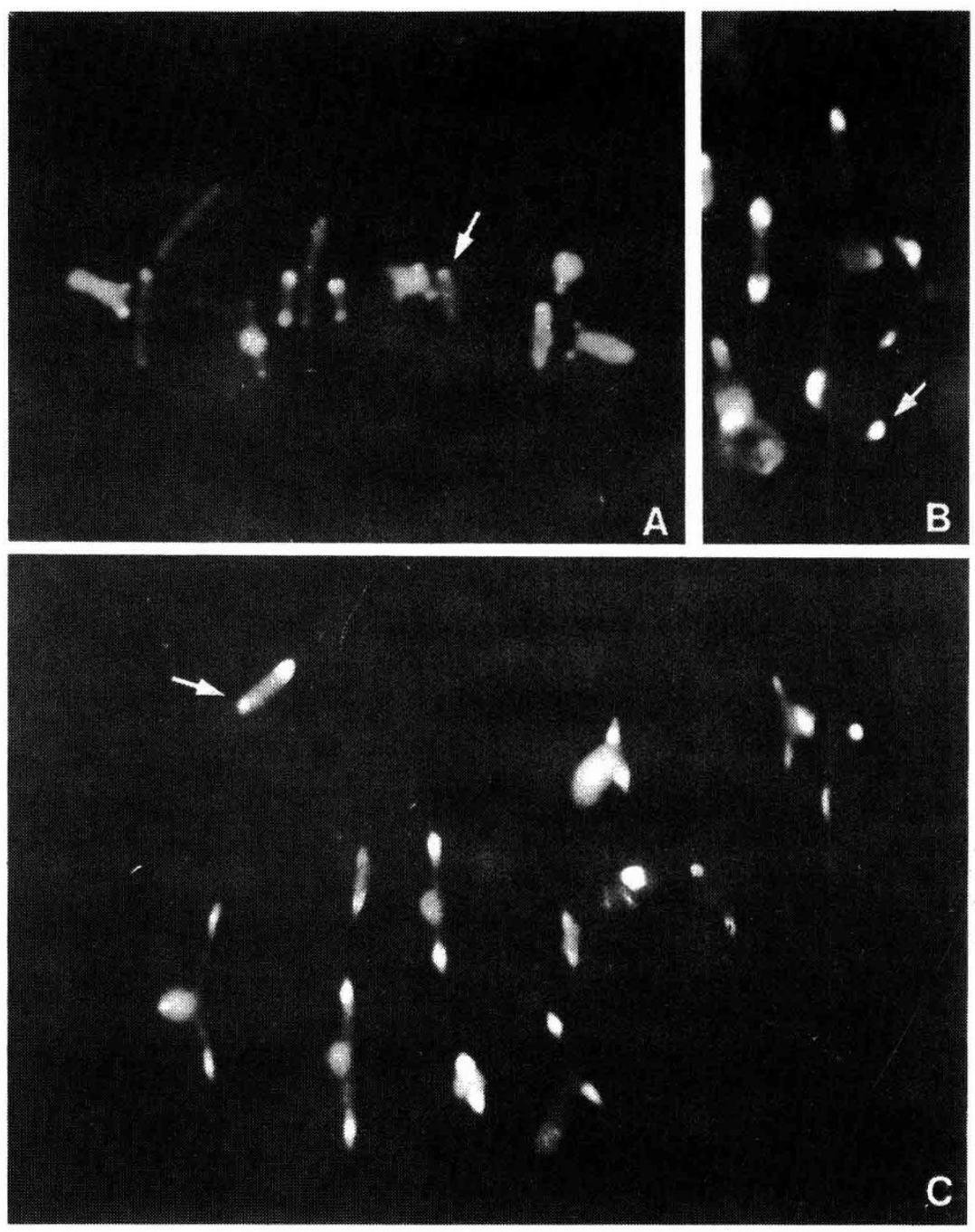

Fig 2. Metaphase-I chromosomes of Podisma after the C-banding plus acridine orange treatment. A) $P$ pedestris from the Pyrenean race. B) Neo-XY bivalent selected from an Alpine male. C) $P$ ignalii carpetana. Arrows indicate the green bright fluorescent bands associated to the NORs.

It is interesting that $P$ ignatii is polymorphic for the size of the GC-rich paracentromeric blocks. In general, the amount of GC-rich paracentromeric heterochromatin is larger than that found in both the Pyrenean race and the Alpine race of $P$ pedestris. This suggests that, in the case of $P$ ignatii, there has been a gain of heterochromatic material with the same characteristics as that preexisting in the genome. This is evidently different from the gain of material in the $P$ pedestris individuals from the Pyrenees. 

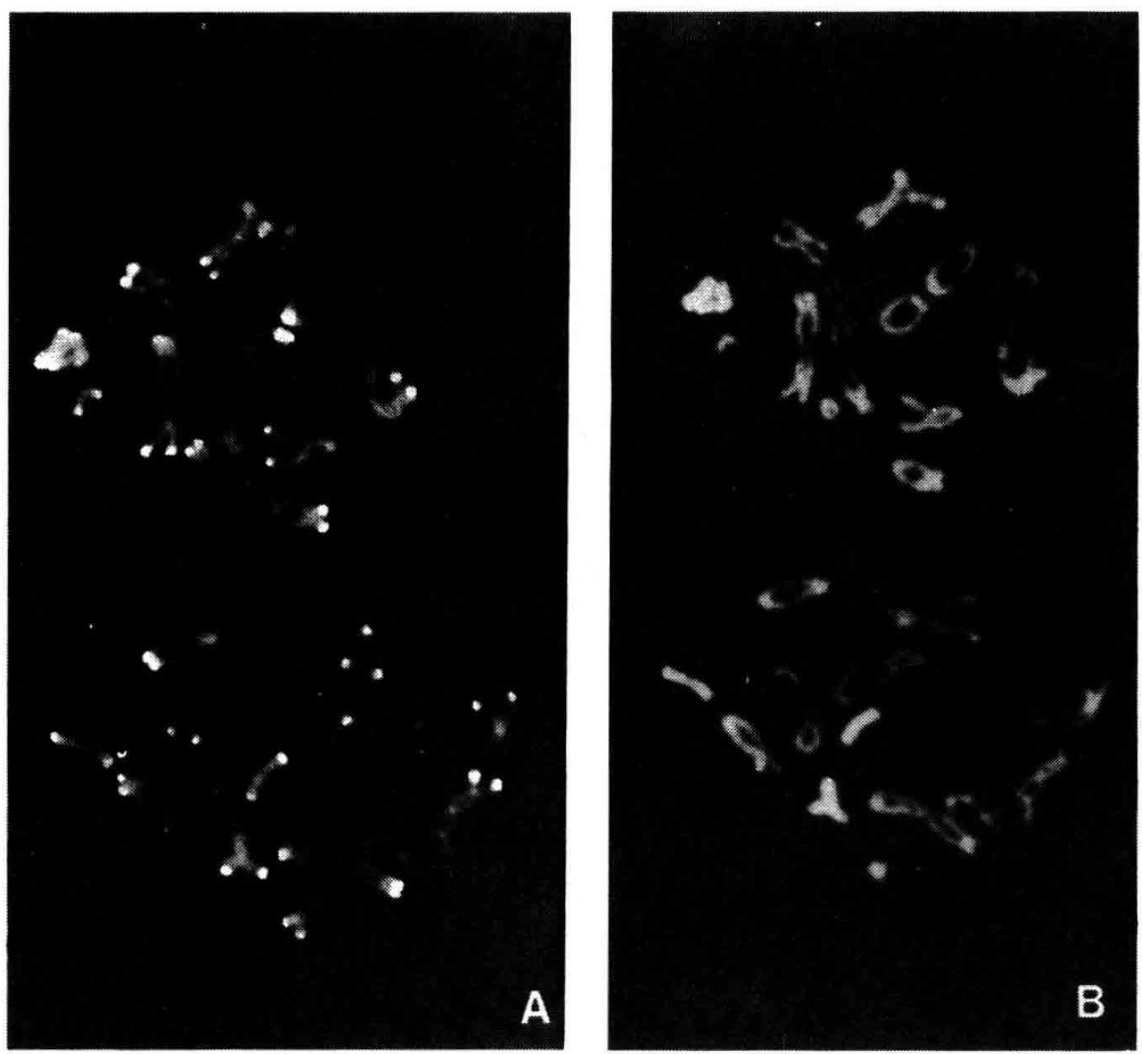

Fig 3. Sequential staining of diplotene bivalents of $P$ ignatii cantabricae with $\mathrm{CMA}_{3}$ (A) and DA/DAPI (B). No differential response to the DA/DAPI is observed.

\section{DISCUSSION}

Comparing these results with those reported by Westerman and Hewitt (1985) and Gosálvez et al (1988), chromosome evolution in Podisma has followed different pathways in the areas of its distribution which have so far been analyzed. One of them involves the autosomes and another involves changes undergone by the $\mathrm{X}$ chromosome. With respect to the autosomes, it is interesting to note the conservatism of the centromeric GC-rich DNA in the individuals from the different geographical regions. Thus, individuals of $P$ pedestris from the Pyrenees appear to add relatively rich $\mathrm{AT}$ repeats to the preexisting $\mathrm{GC}$ heterochromatin. This generates a paracentromeric heterochromatin with a bipartite nature. It is not yet possible to evaluate the role of these differences in evolutionary terms since synthetic hybrids between individuals of $P$ pedestris from the Pyrenees and the Alps display normal meiosis (Gosálvez et al, 1988), and no significant differences in the hatching rate of Pyrenean/Alpine hybrids have been found (Bella et al, 1990). Changes in the patterns of recombination may be correlated with the distal heterochromatic 
segments which are present in the medium-sized chromosomes in individuals from the Alps but not from the Pyrenees or the Sistema Central. In fact, the presence or absence of these heterochromatic regions may dramatically affect the formation of chiasmata in neighbouring euchromatic zones in comparison to chromosomes not showing these regions (Torre et al, 1986; John, 1988). This, in turn, may mean that certain gene combinations are differentially formed and inherited in the different geographical regions.

Active NORs usually have an associated heterochromatic region which shows particular banding characteristics. This suggests that the chromatin forming these regions is of a special nature (Hagele, 1979; Fox and Santos, 1985; Bella et al, 1986). The NOR activity of the $\mathrm{X}$ chromosome in Podisma is quite unusual among acridids. This singular X-NOR, in close relationship with changes in the size and position of the peculiar heterochromatic band associated with it, constitutes an example of the correspondence between location of ribosomal cistrons and its associated band. Although they alter the size of the associated band, the chromosomal rearrangements which have moved the ribosomal cistrons in the $\mathrm{X}$ of Podisma do not change the genetic activity of the ribosomal cistrons, as shown by the similar response to the silver staining in the different cytotypes. The fact that some individuals of Podisma pedestris collected in Valle de Arán do not show an active NOR in the X may be a further step in the apparently complicated development of the polymorphism involving the sex chromosome in this genus. Further work is needed to establish whether this new, anucleolate form of the $\mathrm{X}$ is limited to the Valle de Arán or has a much wider distribution. If this were so, the location of these populations may be centered along the north (French) side of the Pyrenees.

In summary, a series of chromosome differences may have occurred because of the isolation of the different geographical regions currently occupied by Podisma, and the evolutionary link between components of the present distribution is most interesting. There seems that the different races of Podisma have had a large period of evolution in isolation, the absence of gene flow being due to geographical factors, but we are reminded that this divergence could also arise without geographical isolation (Barton and Charlesworth, 1984; Rouhani and Barton, 1987). These different chromosomal forms are currently in contact with each other in some regions and perhaps influence each other's evolution. Anyway, Hewitt (1989) states that hybrid zones are semipermeable to the gene flow, the dynamics of the genes involved being dependent on their own characteristics, thus heterotic, epistatic and neutral genes may show different rates of spread throughout a contact zone. This possible influence could be tested for $P$ pedestris with the hybrid population from the Valle de Arán, characterized by individuals with X-active NOR/X-non active NOR, and with populations from the hybrid zone of the Alps, where neo$\mathrm{XY}$ forms of $P$ pedestris interact with XO forms. It is noteworthy that although the isolation of populations localized in the Alps, Pyrenees, Cantabrian mountains and Sistema Central has arisen independently in a manner probably related to the retreat of the ice at the end of the last glaciation, populations such as those of the Cantabrian mountains and the Sistema Central have followed similar pathways of evolution. These in turn are completely different from those followed by the nearby populations of $P$ pedestris in the Pyrenees. However, the process of evolution has been conservative in the case of the maintenance of the relative GC-richness in 
the heterochromatin of the paracentromeric regions of each chromosome. It is to be hoped that laboratory hybrids between the different chromosomal forms will furnish further evidence concerning the role of karyotypical divergence in the evolution of the genus.

\section{ACKNOWLEDGMENTS}

We are grateful to GM Hewitt for his critical review and PL Mason for his assistance. This work has been supported by a British Council/MEC Fleming fellowship to J de la Torre, and grants from CICYT (PB86-0106, Spain) and EEC (SC1*0127.C Science Program).

\section{REFERENCES}

Barton NH, Charlesworth B (1984) Genetic revolutions, founder effects and speciation. Ann Rev Ecol Syst 15, 133-164

Bella JL, Garcia de la Vega C, López-Fernández C, Gosálvez J (1986) Changes in acridine orange binding and its use in the characterization of heterochromatic zones. Heredity 57, 79-83

Bella JL, Gosálvez J, López-Fernández C, García de la Vega C, Nichols RA, Hewitt GM (1990) Chromosome divergence in Podisma through the Alps, Pyrenees and Sistema Ibérico. Bol Sanit Veg Plagas 20, 349-358

Fox DT, Santos JL (1985) N-bands and nucleolar expression in Schistocerca gregaria and Locusta migratoria. Heredity 54, 333-341

Gosálvez J, de la Torre J, García de la Vega C, López-Fernández C (1986) The effect of double-strength standard saline citrate on silver staining. I. Nucleoli and micronucleoli in the somatic and germ line of the grasshopper Arcyptera fusca. Can $J$ Genet Cytol 28, 219-226

Gosálvez J, Bella JL, Hewitt GM (1988) Chromosomal differentiation in Podisma pedestris: a third race. Heredity $61,149-157$

Hagele K (1979) Characterization of heterochromatin in Schistocerca gregaria by C- and N-banding methods. Chromosoma 70, 239-250

Hewitt GM (1975) A sex chromosome hybrid zone in the grasshopper Podisma pedestris (Orthoptera : Acrididae). Heredity 35, 375-387

Hewitt GM (1989) The subdivision of species by hybrid zones. In: Speciation and its Consequences (Otte D, Endler JA, eds) Sinauer Associates, Sunderland, MA Hewitt GM, Barton N (1981) The structure and maintenance of hybrid zones as exemplified by Podisma pedestris. Insects Cytogenetics. Symp $R$ Entomol Soc London 10 (Blackman RL, Hewitt GM, Ashburner M, eds) Blackwell Scientific Publications, Oxford

John B (1988) The biology of heterochromatin. In: Heterochromatin, Molecular and Structural Aspects (Verma RS, ed) Cambridge University Press, Cambridge

John B, Hewitt GM (1970) Interpopulation sex-chromosome polymorphism in the grasshopper Podisma pedestris. I. Fundamental facts. Chromosoma 31, 291-380

Morales-Agacino E (1950) Breves notas sobre los Podismini de la Península Ibérica (Orthoptera: Acrididae). Eos (spec issue), 367-384 
Rouhani S, Barton NH (1987) The probability of peak shifts in a founder population. J Theoret Biol 126, 51-62

Rufas JS, Esponda P, Gosálvez J (1985) NOR and nucleoli in the spermatogenesis of acridoid species. Genetica 66, 139-144

Schweizer D (1976a) DAPI fluorescence of plant chromosomes prestained with Actimomycin D. Exp Cell Res 102, 408-412

Schweizer D (1976b) Reverse fluorescent chromosome banding with chromomycin and DAPI. Chromosoma 58, 307-324

Torre J de la, López-Fernández C, Nichols R, Gosálvez J (1986) Heterochromatin readjusting chiasma distribution in two species of the genus Arcyptera: the effect among individuals and populations. Heredity 56, 177-184

Westerman M, Hewitt GM (1985) Chromosome banding in Podisma pedestris. Heredity 55, 157-161 